\title{
Association Between Nasal Polyps and Mean Platelet Volume
}

The Editor

Sir,

We have previously reported that mean platelet volume (MPV) is decreased in nasal polyp patients compared to control subjects (1). First of all, we agree with Erdur et al that MPV has not been fully elucidated as an inflammatory marker in certain circumstances. The biological and prognostic value of MPV is still controversial (2) and needs to be validated with prospective randomized controlled trials. However, this retrospective study could be the first step to larger studies aimed at observing the relationship between MPV and inflammation. We also accept that results of MPV studies represent the probability and not the absolute consequences. Methodologies of many studies in literature that observed association between MPV and inflammation are quite similar.

Another issue is that, the control group in our study consisted of healthy subjects without any history of diseases and medication use. We did not wait three months after surgery for the nasal polyp group, on the contrary, blood sample was obtained before surgery for this group. Our study lack postoperative values in patients with nasal polyp. We will compare pre-operative and postoperative MPV values in patients with nasal polyps in a new study in the near future.

Erdur et al is very right about the length of stay of blood samples after obtaining from subjects till whole blood count assay and lack of harmony of haemogram test among different laboratories. Threattle reported that standardization of MPV measurement might allow MPV to have a more broader clinical application (6). We have not stated in the text but all whole blood count assays were done in the laboratories of our institution within minutes after blood sample was obtained.
In conclusion, even though there is enormous data about the association between inflammation and MPV, it is clear that more data from randomized trials are needed for precise evaluation of the role of MPV in inflammatory conditions. We are grateful to Erdur et al for precious criticism of this article.

Keywords: Mean platelet volumem, nasal polyps

G Aktas $^{1}$, A Alcelik $^{1}, M$ Sit $^{2}, H$ Savli $^{1}$

From: ${ }^{1}$ Department of Internal Medicine and ${ }^{2}$ Department of General Surgery, Abant Izzet Baysal University, Bolu, Turkey.

Correspondence: Dr G Aktas, Department of Internal Medicine, 14280, Abant Izzet Baysal University, Bolu, Turkey.Fax: ++03742534615,Email:drgulaliaktas@ gmail.com

\section{REFERENCES}

1. Aktas G, Sit M, Tekce H, Alcelik A, Savli H, Simsek T et al. Mean platelet volume in nasal polyps. West Indian Med J 2013; 62: 515-8.

2. Kiliçli-Çamur N, Kiliç̧i-Camur N, Konuralp C, Eskiser A. Could mean platelet volume be a predictive marker for acute myocardial infarction? Medical science monitor 2005; 11: CR387-CR92.

3. Aktas G, Alcelik A, Tekce BK, Tekelioglu V, Sit M, Savli H. Red cell distribution width and mean platelet volume in patients with irritable bowel syndrome. Przeglad gastroenterologiczny 2014; 9: 160-3.

4. Polinska B, Matowicka-Karna J, Kemona H. Assessment of the influence of the inflammatory process on the activation of blood platelets and morphological parameters in patients with ulcerative colitis (colitis ulcerosa). Folia Histochem Cytobiol 2011; 49: 119-24.

5. Sit M, Aktas G, Dikbas O, Alcelik A, Savli H. Mean platelet volume should be a useful indicator in diagnosis of Hashimoto's Thyroiditis. Acta Medica Mediterranea 2014; 30: 1263-6.

6. Threatte GA. Usefulness of the mean platelet volume. Clin Lab Med 1993; 13: 937-50. 